NOTICE: this is the author's version of a work that was accepted for publication in the Journal of Petroleum Science and Engineering. Changes resulting from the publishing process, such as peer review, editing, corrections, structural formatting, and other quality control mechanisms may not be reflected in this document. Changes may have been made to this work since it was submitted for publication. A definitive version was subsequently published in the Journal of Petroleum Science and Engineering, Vol.109, (2013). DOI: 10.1016/j.petrol.2013.08.011 


\title{
Design Concept for Implementation of a novel subsea gas dehydration process for a gas/condensate well
}

\author{
David Parks ${ }^{\mathrm{a}}$ and David Pack
}

\begin{abstract}
Natural Gas usually contains significant quantities of water vapour, which must be removed for gas processing and transmission. Common allowable water content of transmission gas ranges from 4 to 7 pounds per MMSCF (64 to $112 \mathrm{mg} / \mathrm{m}^{3}$ ). Failure to sufficiently reduce the water content can lead to condensation of liquid water and the formation and accumulation of gas hydrates into pipe blocking plugs. This is particularly important for subsea pipelines with the high pressure and low temperatures conditions that exposes the gas to hydrate formation conditions.
\end{abstract}

To meet the demands of deeper and more remote reservoirs, subsea processing has been poised as one of the most potentially promising technology developments in the offshore development.

A novel dehydration solution that is applicable for subsea installation has been designed and tested in the laboratories of Clean Gas Technology Australia department of Curtin University. The solution utilises the concepts of gas cooling through expansion and the controlled formation and management of gas hydrates to reduce the water content of a saturated gas stream to levels suitable for gas transport in subsea pipelines. The pilot plant implemented to test the solution design at pressures up to $10 \mathrm{MPa}$ (1469psi) and flow rates of $35 \mathrm{std} \mathrm{m}^{3} / \mathrm{hr}$ (30MSCFD) demonstrated that dehydration performance better than achieved with batch experiments was achievable.

This paper describes a design methodology to migrate the process to a subsea implementation and presents a model for a production implementation using the experimentally obtained dehydration performance, demonstrating that it can provide a viable subsea dehydration solution.

KEYWORDS: Dehydration, Natural Gas, Hydrates, Joule-Thomson

Page | 1 
a Petroleum Engineering department, Curtin University, GPO Box U1987 Perth, WA 6845, Australia, Telephone: +61 892663497 Facsimile: +61 89266 4848, D.Parks@curtin.edu.au (corresponding author)

b Petroleum Engineering department, Curtin University, GPO Box U1987 Perth, WA 6845, Australia, D.Pack@curtin.edu.au 


\section{Introduction}

Worldwide, it is an estimated that there are over 4,000TCF $\left(110 \times 10^{12} \mathrm{~m}^{3}\right)$ of gas in gas fields where the large capital and operating costs experienced with platform based processing solutions cannot be economically justified. (Verghese 2003) To exploit these resources cheaper solutions such as subsea completions and processing will be required and pipelines utilised to transport the gas to shore or centralised platforms.

In a previous paper by Parks 2012 a novel subsea gas dehydration process was described and the dehydration results presented. The experimental dehydration system that is illustrated in Figure 1 comprised of four subsystems:

- a high pressure gas delivery system to provide a constant source of natural gas at variable pressures up to $10 \mathrm{MPa}$ (1470psi) and constant flow rates up to 35 standard $\mathrm{m}^{3}$ per hour (30MSCFD);

- a gas conditioning system to fully water saturate and sets the temperature of the inlet gas stream;

- the gas dehydration system; and

- the system instrumentation to monitor and record all dehydration system operations.

The dehydration process utilises expansion of natural gas and the Joule-Thomson effect to cool the gas. After expansion through a choke the gas becomes supersaturated with water vapour and water condenses out reducing the water content of the gas. By pre-chilling the inlet gas the resultant gas temperature and pressure after expansion is within its hydrate formation region and hydrates form within the dehydration vessel.

Batch experiments have demonstrated that Natural gases in equilibrium with Hydrates have lower water content than when Hydrates are not present. During the experiments performed it was demonstrated that for a continuous process the hydrate depression of water content was also 
achievable. The results of the continuous process experiments were comparable with those achieved in batch experiments.

For gas to be transported by a subsea pipeline the water content must be low enough to ensure that further condensation of water cannot occur and the resultant hydrate blockage and corrosion problems can be avoided. The results of the previous dehydration experiments performed by the author are plotted in Figure 2. This figure also shows the minimum pipeline dewpoint for natural gasses to be transported without threat of hydrate formation for subsea temperatures down to $4 \mathrm{C}$ (39F), a temperature often encountered in deep water situations. The achieved dehydration is clearly suitable for pipelines in subsea conditions down to 4C (39F).

The purpose of this paper is to take the experimental system and results and to demonstrate how the process could be migrated to a real subsea implementation.

\section{Subsea dehydration system implementation}

To obtain optimal dehydration performance the gas stream feed to the dehydration vessel will need to be preconditioned to remove solids and liquids from the well stream and to ensure the gas feed is at the optimum inlet temperature. The inlet temperature needs to be as low as possible whilst maintaining the feed outside of hydrate formation conditions. The low inlet temperature ensures that a minimum of pressure drop is utilised by the process to obtain the required conditions within the dehydration vessel.

A simplified schematic of the proposed subsea dehydration system is shown in Figure 3.

To precondition the gas stream a combination of separators and adjustable heat exchangers is proposed:

- Wellhead separator to remove entrained fluids and solids from the well stream 
- An adjustable heat exchanger to cool the well stream to the optimal dehydration inlet temperature required

- An inlet separator to remove liquids that dropped out of the gas stream as it was cooled in the heat exchanger.

Temperature sensors, control circuits and actuators will be utilized to monitor and control the adjustable heat exchanger utilizing some of the cold dehydrated gas to condition the inlet gas stream.

Several subsea separator trials have been performed around the world, including the Pazflor project at $800 \mathrm{~m}$ (2635ft) depth in Angola (Riviere 2009) and the VASPS project at $400 \mathrm{~m}$ (1317ft) depth in Brazil (Baker and Entress 1991). Also a commercial scale subsea separation system was implemented in 2007 with a three-phase separator solution in $200 \mathrm{~m}$ of water at the Tordis field in the North Sea (Parshall 2008; Vu, Fantoft et al. 2009).

For the adjustable heat exchanger it is envisaged that a two stage design will be the most appropriate approach. The first stage would provide the bulk of the cooling required but have limited adjustability and the second stage would provide the fine adjustment of the gas temperature by utilising some of the cold processed gas.

The gas stream leaving the heat exchanger will be significantly cooler than that at which it entered saturated with water vapour. As a consequence some liquids will have condensed from the gas stream and will need to be removed before the gas stream is passed to the dehydration vessel.

The inlet separator captures the condensate and water and from the heat exchanger outlet stream. The Inlet separator may be a 2 or 3 phase separator depending on the gas composition, the inlet temperature and wether condensate removed from the gas stream is being recovered or disposed of with the water. 
The dehydration vessel relies on the presence of hydrates within the vessel to decrease the water content of the gas stream. As the system operates hydrates will continue to build up within the vessel and if not removed would ultimately cause a system blockage. A critical design element of the dehydration vessel is a hydrate management subsystem to monitor and control the amount of hydrate present within the vessel.

A possible design configuration of a production dehydration vessel is shown in Figure 4. The major subsystems incorporated in this design are:

- Insulated pressure vessel

- Heated inlet nozzle

- Hydrate management system

- Hydrate dissociation system

The operating temperature of the dehydration vessel will be lower than the seawater temperature so to ensure maximum thermal performance of the dehydration vessel it will need to be suitably insulated. Polyurethane foam insulation was used successfully with the experimental vessel and being already widely used for insulation in subsea environments, it would likely be an appropriate choice of material for the dehydration vessel.

After system shut-in and subsequent cold start the first gas passing to the dehydration vessel will be at close to the temperature of the surrounding seawater. At these low gas inlet temperatures experience from the experimental runs tells us that it is highly likely that on commencement of cooling operations that hydrates will form and will block the nozzle. To prevent hydrate build-up in the nozzle the ability to heat the nozzle will be required.

During the experimentation phase, nozzle heating and inlet gas temperature control were both found to be applicable methods of ensuring constant gas flow and optimum cooling within the 
dehydration vessel. With good thermal design, gas temperature control with the inlet heat exchangers has a much slower response time than a nozzle heater. As a consequence of its fast response time, the heated nozzle facility may be beneficial to reliable system operations, particularly if sudden changes to gas stream properties occur.

\subsection{Hydrate management system}

Hydrate build up on the dehydration vessel walls is critical to ensuring gas hydrate contact and the depression of the gas stream water contact.

The proposed approach to control the temperature environment within the dehydration reactor is to use solid-state Peltier devices together with control circuits. Peltier devices are layered heat pump devices that can transfer heat from one external face to the opposite external face. The direction of heat transfer is controlled by the direction of current flow, so in a fixed configuration a face can be made to cool or heat relative to the other face simply by controlling the current flow.

Peltier controlled plates fitted inside the dehydration reactor could be used to alternately cool then heat the faces to first encourage hydrate formation and then to remove the hydrate sheet from the face for dissociation in the bottom of the reactor vessel.

Multiple Peltier based cooling plates could be fitted around the internal face of the reactor as shown in the vessel cross-sectional illustration shown in Figure 5.

Each module would be a subassembly comprising the two heat transfer plates with a number of Peltier devices sandwiched between them. Control electronics would be required to control the operation of each Cooling module. The operational cycle would be:

1. At system start-up, all modules will be placed in cooling mode some time before gas flow commences and allowed to stabilize at a temperature low enough to allow fast initiation of hydrate formation. 
2. Gas flow commences and hydrates will build up on the controlled plate of the cooling modules.

3. At regular intervals a proportion of the cooling modules are switched to heating mode. The cooling face heats up and the hydrates on the surface of the plate will dissociate. With the release of gas from dissociation and the formation of a water film the sheet of hydrates on the cooling module will fall under gravity to the bottom of the dehydration vessel. Once the hydrate sheet is released the cooling module reverts to cooling mode.

The functions of the control electronics will be:

1. Monitor temperatures of module and module operational status

2. Control direction and level of module operating current to allow cooling and heating at determined levels to be applied.

3. Implement timing protocols to cycle modules through the cooling/heating cycles.

The implementation can include significant system redundancy to ensure that the operational life of the Dehydration system is not compromised by failure of an electronic component.

The solution requires no moving parts and has the potential to provide long operating life in the harsh deep sea operating environment.

\section{Thermal design considerations}

Considering the thermal design of the proposed solution, there are two states of particular interest that need to be analysed, the point at which the hydrate build-up has reached the desired thickness for the removal process to commence and the state once the hydrate has dropped from the plate. These are illustrated in Figure 6.

With a temperature sensor fitted close to the inside face of the metal plate we can measure the temperature of the steel-hydrate interface. The thermal conductivity of hydrate is approximately Page $\mid 8$ 
100 times less than that of carbon steel $(0.5 \mathrm{~W} / \mathrm{m} . \mathrm{K}$ (Carroll 2003) versus $\sim 54 \mathrm{~W} / \mathrm{m} . \mathrm{K}$ ) so even with a small heat flow the temperature of the interface will change markedly as the hydrate layer thickens.

When the hydrate has reached a predetermined thickness the process of removing it by adding heat with the Peltier devices will commence. The temperature of the steel-hydrate interface must be raised to above the hydrate formation temperature at the vessel pressure to cause the hydrate at the interface to dissociate.

As heat is applied, a temperature gradient will establish across the plate and hydrate according to the thermal conductivities of the materials. The low thermal conductivity of the hydrate causes it to act like an insulator so the steel-hydrate interface will heat up quickly with minimal heat transfer through the hydrate to the gas in the vessel. When the plate-hydrate interface the dissociation temperature the hydrate at the interface will melt and release the trapped gas at high pressure. This high pressure gas should assist in the removal of the hydrate from the steel plate.

Looking at the thermal characteristics, while the hydrate is present on the plate the overall thermal coefficient is calculated to be around $25 \mathrm{~W} / \mathrm{m}^{2} \mathrm{~K}$ and when it has been removed this doubles to $50 \mathrm{~W} / \mathrm{m}^{2} \mathrm{~K}$. As the heating power will be kept constant this change in the thermal coefficient will cause a large drop in the temperature differential between the plate and the gas. This will provide an excellent marker to the control electronics to stop heating and start chilling the plate.

With the described hydrate capture mechanism, periodic cycling of the capture plates will result in sheets of hydrate detaching from the plates and falling to the bottom of the dehydration vessel.

The proposed dehydration vessel will have a horizontal separator at the bottom filled with condensate warmed to just above the hydrate dissociation temperature. The hydrate typically has a higher density than the condensate so will sink into the condensate layer and will dissociate. As it dissociates the released water will sink to the bottom of the separator and the gas will bubble through the condensate to the top of the vessel where it will re-join the gas stream.

Page | 9 
Only thermodynamic processes are proposed to be used to cool the gas stream from the well, no power is proposed to be used for continuous refrigeration. A major consequence of this is that the power requirements of the process are relatively small. Power is needed in the system for the following functions:

- to remove the hydrate from the capture plates through electrically generated heat using the Peltier heat pumps

- to cool the capture plates once the hydrate sheets have been dropped

- to warm the condensate bath where the hydrates dissociate.

- nozzle heating at start-up and also potentially for short periods during operations as required.

- for the monitoring and control systems including valve actuators on the heat exchangers and dehydration vessel

Subsea power may be obtained through an umbilical or may be generated subsea.

\section{Model}

To determine the practicality of the proposed dehydration system concept a model of the process has been developed using HYSYS and a moderate sized gas/condensate well stream. The HYSYS (Aspen Technology Inc 2003) model of the subsea system is shown in Figure 7, the well stream composition in Table 1 and wellhead conditions in Table 2. For simplicity components heavier than decane were removed.

Considering the inlet heat exchanger, the first stage in the model comprises of a section of pipeline surrounded by low ambient temperature sea water. The second heat exchanger stage comprises of a tube-shell heat exchanger with the gas to be cooled passing through the tubes and the shell fed with a proportion of the cold gas exiting the dehydration vessel outlet. The bulk of the cooling would be Page | 10 
performed by the pipeline exchanger and the fine temperature adjustment performed by the tubeshell heat exchanger.

Using this approach allows for some variation in seawater temperatures, speed of seawater currents and gas stream flow rates whilst still being able to maintain an accurate setting of the inlet gas temperature to the dehydration vessel.

The overall heat transfer coefficient of the tubing section to the seawater can be expressed by the equation (Incropera and De Witt 1985):

$$
U=\frac{1}{\frac{1}{h_{1}}+\frac{r}{k} \ln \frac{r+t}{r}+\frac{r+t}{r} \frac{1}{h_{2}}}
$$

For turbulent flow in the piping, the Dittus-Boelter correlation can be used to calculate the forced convection coefficient $h_{1}$ for the natural gas to tubing:

$$
h_{1}=\frac{k_{f}}{D_{H}} N u
$$

where $k_{f}$ is the thermal conductivity of the fluid, $D_{H}$ is the hydraulic diameter and $\mathrm{Nu}$ is Nusselt number which for cooling can be expressed by the equation:

$$
N u=0.023 \operatorname{Re}^{0.8} \operatorname{Pr}^{0.33}
$$

where Re is the Reynolds number: $\quad \operatorname{Re}=\frac{Q D_{H}}{v A}$

and $\operatorname{Pr}$ is the Prandtl number

$$
\operatorname{Pr}=\frac{c_{p} \mu}{k}
$$

For the purpose of the sizing estimate it is assumed that the pipeline heat exchanger will reduce the gas from the wellhead temperature of $80 \mathrm{C}(176 \mathrm{~F})$ to $28 \mathrm{C}(82 \mathrm{~F})$ and the tube shell heat exchanger will 
further reduce the temperature to the required $25 \mathrm{C}(77 \mathrm{~F})$ as the feed temperature to the dehydration vessel.

Using the defined well parameters we can use the above equations to calculate the convection coefficient for the natural gas. Assuming the heat exchanger consists of a single length of pipe the calculated value for the coefficient $h_{1}$ is over $500 \mathrm{~W} / \mathrm{m}^{2} \mathrm{~K}$. This is over an order of magnitude greater than the conduction coefficient for the steel tubing (For carbon steel $k$ is taken to be $43 \mathrm{~W} / \mathrm{m} . \mathrm{K}$ ) and the likely convection coefficient for the seawater so can largely be ignored when calculating the overall heat transfer coefficient of the heat exchanger.

The convection coefficient for the seawater surrounding the heat exchanger is a function of a number of factors some of which are unknown including the heat exchanger orientation and the subsea flow environment i.e. local current. In literature, typical coefficients for free convection of water between 20 and $100 \mathrm{~W} / \mathrm{m}^{2} . \mathrm{K}$ are stated. For the purpose of this sizing estimate an assumed convection coefficient, $h_{2}$ of $50 \mathrm{~W} / \mathrm{m}^{2} . K$ has been used.

The total heat transfer coefficient for the heat exchanger tubing, $U$ is then calculated as $45.7 \mathrm{~W} / \mathrm{m}^{2} \mathrm{~K}$.

Using Schedule 160, 24 inch mild steel piping and the defined well parameters a heat exchanger made of 1 pipe of 293 metres (961 feet) in length would reduce the inlet temperature from $80 \mathrm{C}$ $(176 F)$ to $28 \mathrm{C}(82 \mathrm{~F})$ in seawater of $4 \mathrm{C}(39 \mathrm{~F})$. With the addition of heat sinks to the external surface of the pipe the thermal conductivity between the pipe and the seawater could be improved and a shorter length of piping would suffice. The ability to add or remove heat sinks could be beneficial when installing the pipe heat exchanger and tuning its performance.

The HYSYS model was used to estimate the size of the required tube-shell heat exchanger using a simple 'Steady State' model. To size the heat exchanger, HYSYS requires the overall heat transfer coefficient for the heat exchanger. From the flow conditions in the tubes and the shell of the heat exchanger this was calculated to be $550 \mathrm{~W} / \mathrm{m}^{2} . \mathrm{K}$

Page | 12 
The resultant design parameters for a heat exchanger suitable to meet the design requirements are summarised in Table 3.

For the worked scenario, enough hydrocarbon liquids are present in the fluid stream leaving the heat exchanger so a 3-phase separator would probably be appropriate. Table 4 lists the properties of the stream leaving the heat exchanger.

The experimental results of our dehydration experiments concluded that it was possible to obtain dehydration performance with the constant flow process through the dehydration vessel comparable with that achieved in batch experiments.

When we look at the inlet temperature and pressure and the pressure drop across the inlet nozzle we can calculate the gas temperature and pressure within the dehydration vessel. From published results on batch experiments we can then predict the likely water content of the gas stream leaving the dehydration vessel.

The operating conditions, parameters and predicted results are summarised in Table 5.

The measured JT coefficient during experiments was 4.4 K/MPa compared to the HYSYS prediction of 4.8 K/MPa. Assuming we can achieve similar performance in a production system with a pressure drop of 8.9MPa the vessel temperature is estimated to be $2.6 \mathrm{C}$.

From the correlation developed by Chapoy (Chapoy, Mohammadi et al. 2004) using the vessel pressure of $6 \mathrm{MPa}(881 \mathrm{psi})$ we can plot the predicted water content versus the vessel temperature as shown by Figure 9.

At the predicted vessel gas temperature of $2.6 \mathrm{C}(36.7 \mathrm{~F})$ the predicted water content of the gas leaving the dehydration vessel will be $113 \mathrm{mg} / \mathrm{m}^{3}$ (7lb/MMSCF) equivalent to a dewpoint of $-38.6 \mathrm{C}$ $(-37.5 F)$. 
Figure 10 shows a plot of the predicted dewpoint on the curve of maximum gas stream dewpoint for variable pipeline pressures at the ambient seawater temperature of $4 \mathrm{C}(39.2 \mathrm{~F})$. The predicted dewpoint is below the maximum gas stream dewpoint for a pipeline running at $6 \mathrm{MPa}$ (881 psi) and seawater of $4 \mathrm{C}(39.2 \mathrm{~F})$, so water will not condense out of the gas as it passes through the pipeline. Experimentally we managed better water reduction than predicted by the Chapoy correlation so we could expect an even better margin than shown here.

The properties of the streams leaving the dehydration vessel are shown in Table 6 and the outlet streams in Table 7

Using the data from the HYSYS model we can make some estimates on the power requirements of the hydrate management system

To remove the hydrates from the plates, power will be required to heat up the plate and to provide sufficient heat to melt a thin layer of the hydrate at the steel-hydrate interface. Assuming a plate thickness of $10 \mathrm{~mm}$, the heat required to warm the plate from an estimated ambient temperature of $2.6 \mathrm{C}(36.7 \mathrm{~F})$ to the hydrate dissociation temperature of $15.6 \mathrm{C}(60 \mathrm{~F})$ will be $585 \mathrm{~kJ}$ per square metre of plate. If a typical plate was $100 \mathrm{~mm}$ wide by $200 \mathrm{~mm}$ high and $1 \mathrm{~mm}$ of hydrate has to be melted for the hydrate sheet to detach itself from the plate a total of $23 \mathrm{KJ}$ of energy will be required.(The hydrate heat of formation is $500 \mathrm{~kJ} / \mathrm{kg}$ (Sloan and Koh 2008)). On a plate of these dimensions, Peltier devices capable of providing 300W of heat could easily be fitted. The time then taken for these devices to provide the required energy to remove the hydrate sheets is less than 2 minutes.

In the worked scenario the inlet gas stream entering the dehydration vessel will be saturated with water. At a pressure of $14.9 \mathrm{MPa}$ (2188psi) and temperature of $25 \mathrm{C}(77 \mathrm{~F})$ the saturated gas stream contains $320 \mathrm{mg} / \mathrm{m}^{3}$ (21lb/MMSCF) of water vapour. At the dehydration vessel exit conditions of 6.0MPa (881psi) and $2.6 \mathrm{C}(36.7 \mathrm{~F})$ the predicted water content will be $113 \mathrm{mg} / \mathrm{m}^{3}$ so a total of 
$207 \mathrm{mg} / \mathrm{m}^{3}$ of water will be removed from the gas stream within the dehydration vessel. For the scenario flow rate at the dehydration vessel of 3,920 kgmol/hr, the total water capture is $19.21 / \mathrm{hr}$.

Some of this captured water will be collected as water droplets falling by gravity to the bottom of the vessel and some as hydrate build-up on the walls of the vessel. If we assume the production vessel has the same dimensional scale as the experimental system the total area of capture plates will be around $75 \mathrm{~m}^{2}$. If $90 \%$ of the water is captured on these plates as Hydrate the capture rate will be around 24.5litres per hour. The time to capture a uniform $1 \mathrm{~cm}$ thick layer of Hydrate across the area of plates in the dehydration will be 31 hours. The likelihood of uniform capture is small but this calculation illustrates the slow rate of hydrate build up compared to the rate at which it can be efficiently removed.

\section{Summary of system for production operations}

This paper has presented a potential implementation scenario for a medium sized gas-condensate well. The complexity of the solution is low, making use of components that are already industrially proven and many that are already in use subsea.

- Subsea separators similar to those already in operation should be applicable

- The heat exchanger uses moderate lengths of pipe and a standard tube-shell component.

- The dehydration vessel is a pressure vessel similar to a separator with an internal hydrate management system that uses proven solid state components. It has no moving parts.

- Existing techniques can be used for power generation and effluent disposal.

The concept is considered applicable for many subsea applications but does require certain considerations to be met 
- The Joule-Thomson coefficient must be sufficiently positive to ensure sufficient cooling occurs without requiring an excessive pressure drop through the process

- The wellhead pressure must be high enough to ensure transfer through pipelines is economic after the process pressure drop

- Seabed temperature conditions can support the preconditioning process

There is still a significant amount of research work that needs to be performed to fully confirm the viability of the proposed approach but the calculations presented suggest strongly that the approach is likely to be a practical approach to exploiting some sub-sea gas fields that cannot justify a platform installation.

\section{References}

Aspen Technology Inc, C., Massachusetts, USA (2003). Aspen HYSYS, Version 2006.5 [21.0.0.6924], Aspen Technology Inc.

Baker, A. C. and J. H. Entress (1991). The VASPS Subsea Separation and Pumping System Applied to Marginal Fied Developments. Offshore Europe Conference. Aberdeen, Scotland, SPE.

Carroll, J. J. (2003). Natural Gas Hydrates: A Guide for Engineers, Gulf Professional Publishing.

Chapoy, A., A. H. Mohammadi, et al. (2004). "Gas Solubility Measurement and Modeling for Methane-Water and Methane-Ethane-n-Butane-Water Systems at Low Temperature Conditions." Fluid Phase Equilibria 220: 113-121.

Incropera, F. P. and D. P. De Witt (1985). Fundamentals of Heat and Mass Transfer, John Wiley \& Sons. 
Parks, D. and R. Amin (2012). "Novel subsea gas dehydration process, the process plant and dehydration performance." Journal of Petroleum Science and Engineering 81(0): 94-99.Parshall, J. (2008). "Evolving Subsea Technology Tackles Huge New Risks of Today's Projects." JPT(May 2008): 40-47.

Riviere, L. (2009). "Pazflor Applies World's First Large-Scale Subsea Separation System." Offshore 69(5).

Sloan, E. D. and C. A. Koh (2008). Clathrate Hydrates of Natural Gases, CRC Press.

Verghese, J. T. (2003). Options for Exploiting Stranded Gas - An Overview of Issues, Opportunities and Solutions. SPE Annual Technical Conference and Exhibition. Denver, Colorado, USA.

Vu, V. K., R. Fantoft, et al. (2009). Comparison of Subsea Separation Systems. 2009 Offshore Technology Conference. Houston, Texas, USA.

\section{Acknowledgements}

I should like to acknowledge Woodside Ltd for providing the funding for this research. 


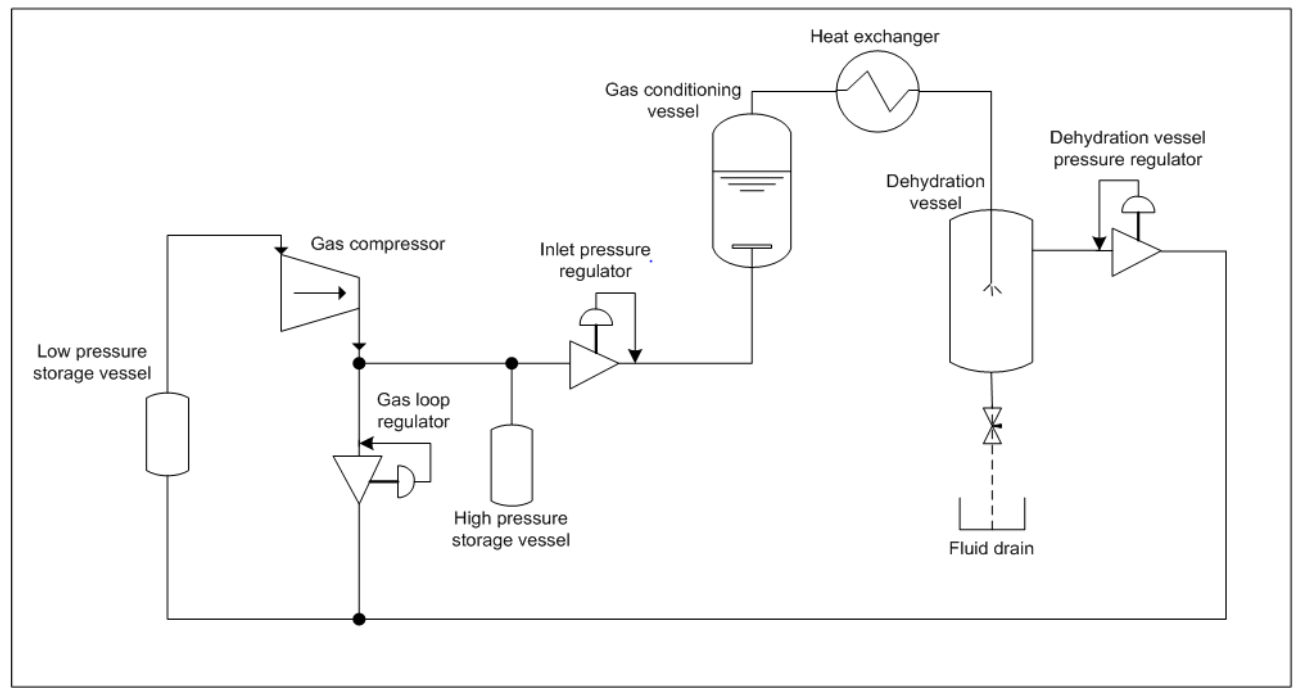

Figure 1: Dehydration pilot plant schematic diagram 


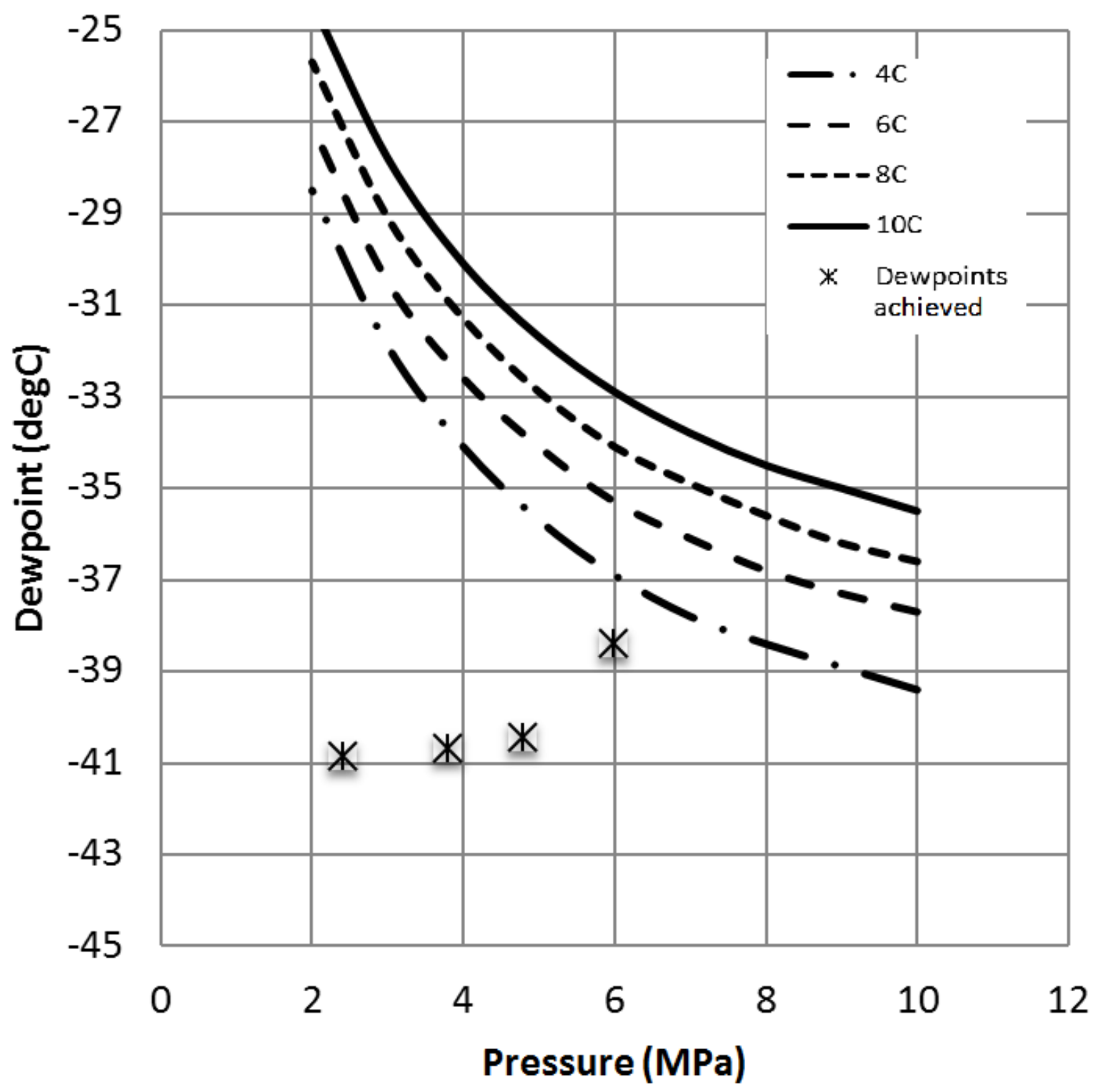

Figure 2: Experimental dehydration results and subsea pipeline dewpoint requirements 


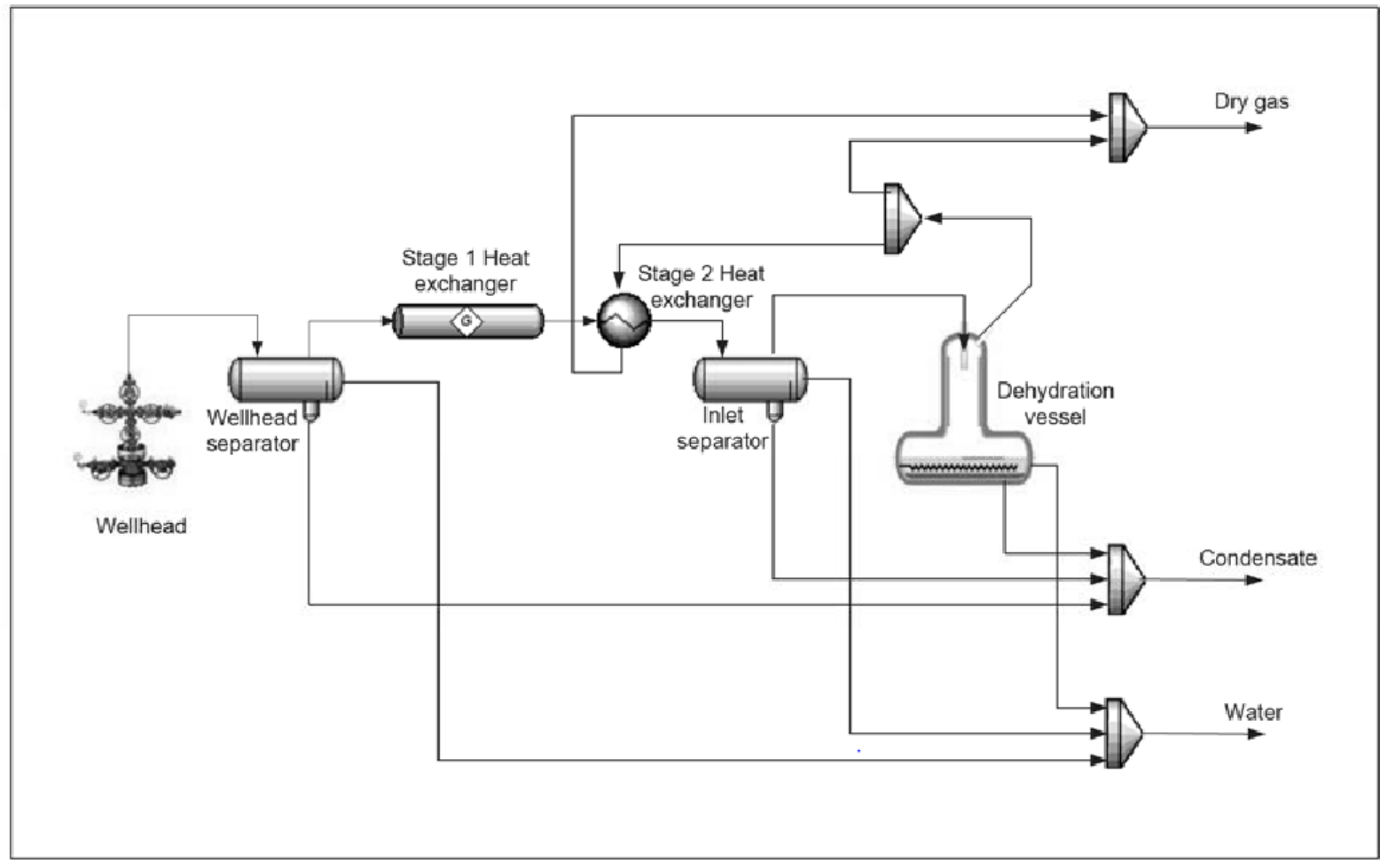

Figure 3: Simplified schematic of production subsea dehydration system 


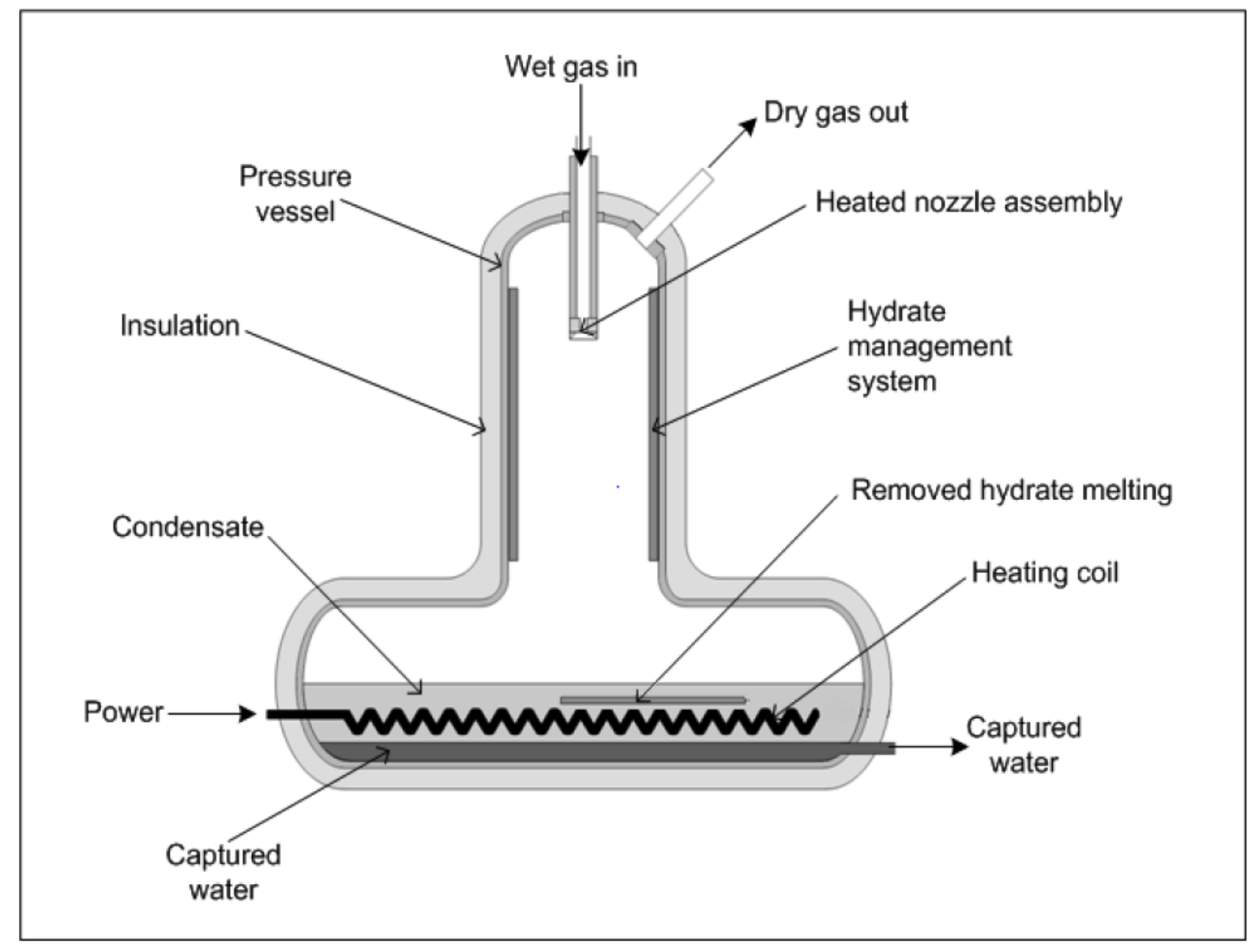

Figure 4: Production dehydration vessel configuration 
Pressure vessel cross-section

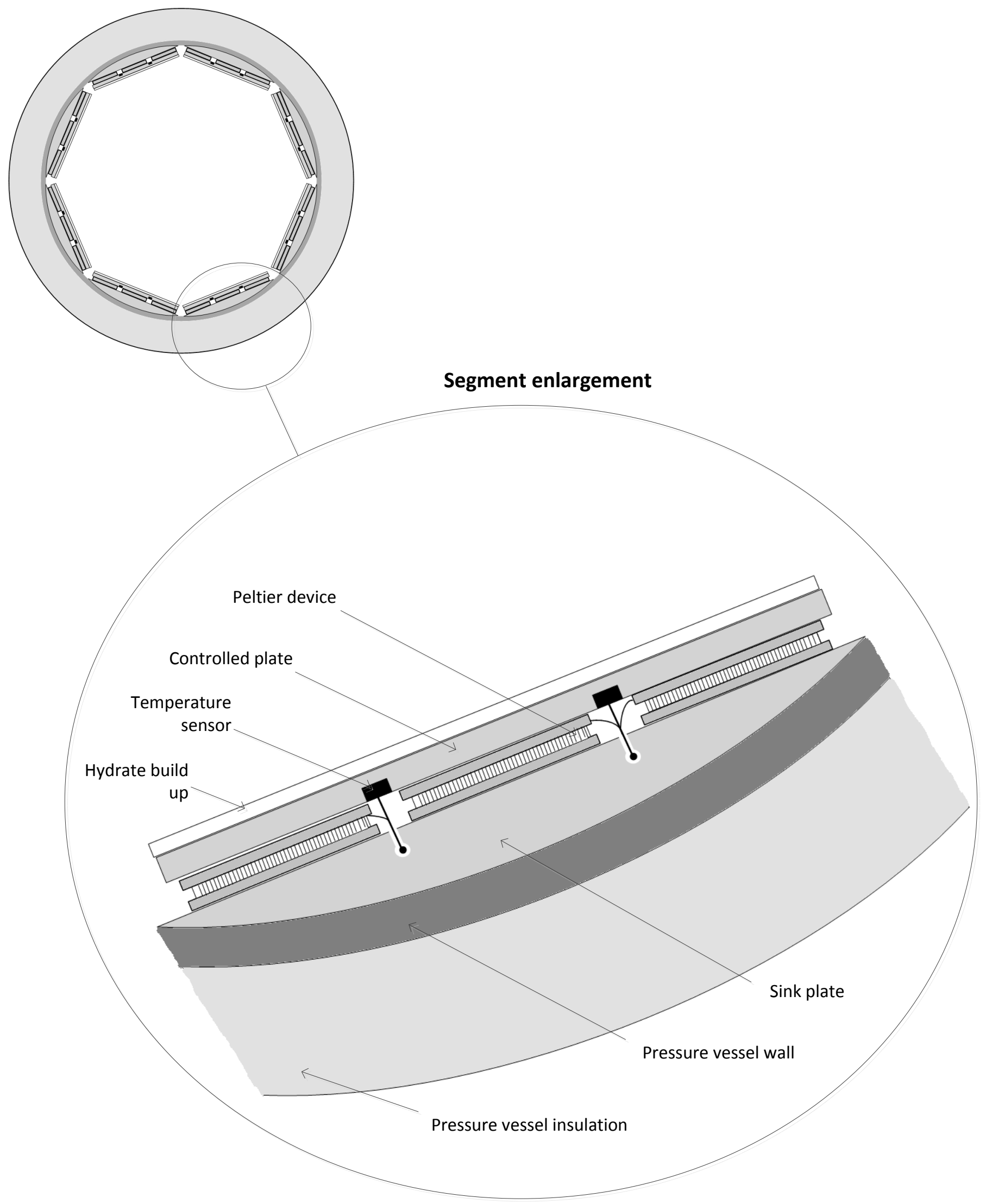




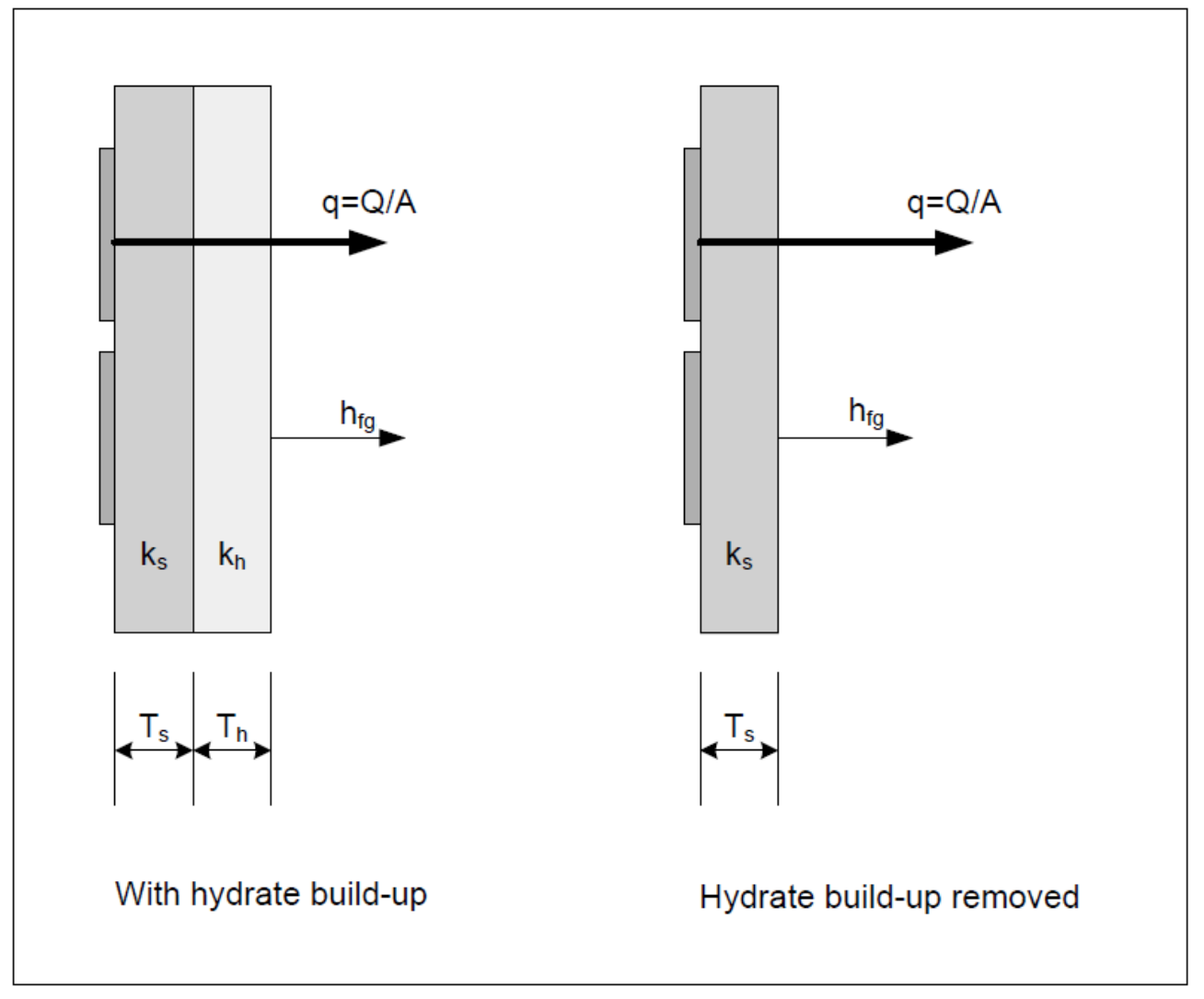

Figure 6: Thermal layers within dehydration vessel 


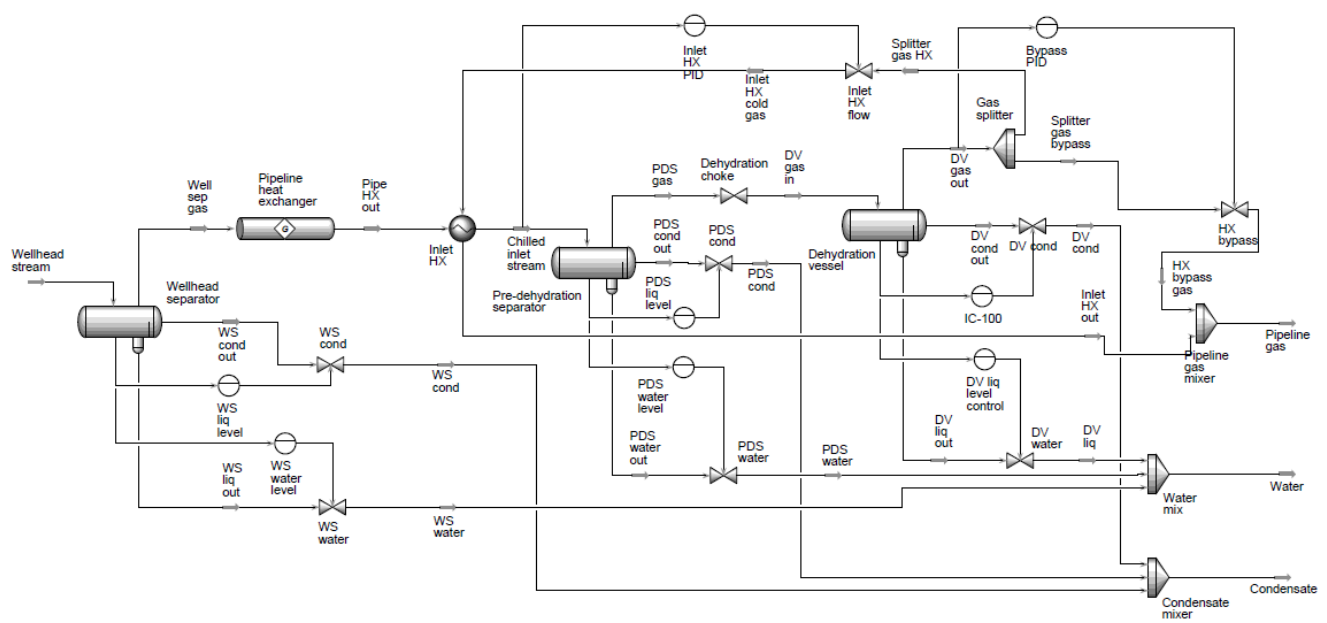

Figure 7: HYSYS model of subsea gas dehydration system 


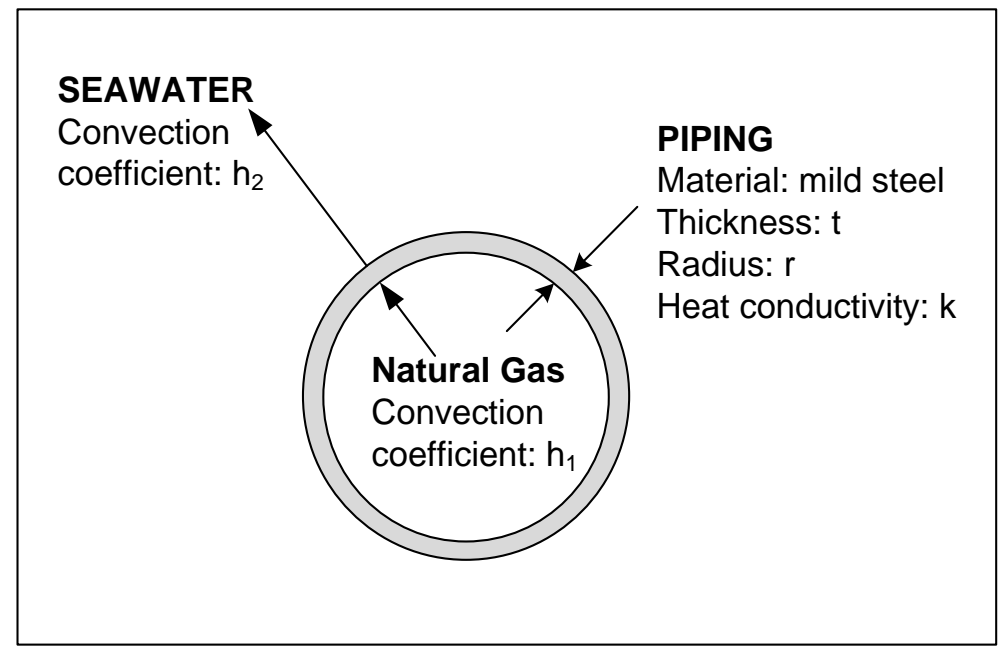

Figure 8: Heat exchanger section and parameters 


\section{Predicted water content (gas pressure 6MPa)}

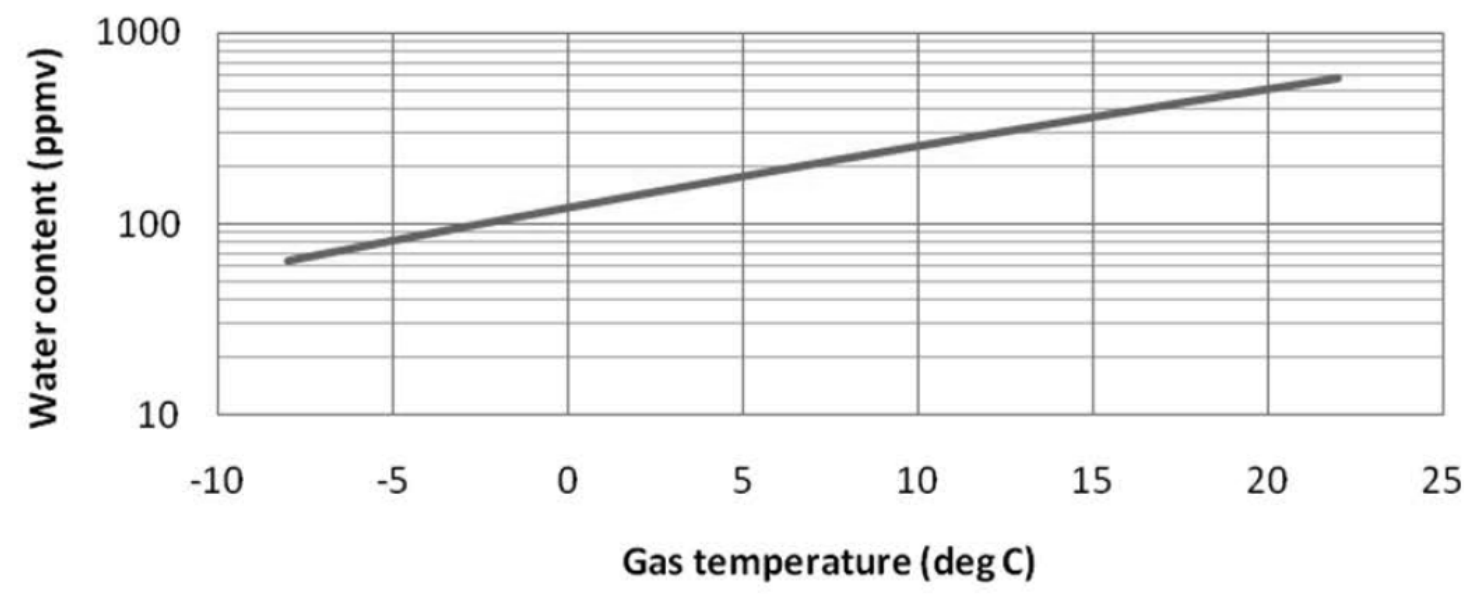

Figure 9: Predicted water content of gas stream leaving dehydration vessel at $6 \mathrm{MPa}$ vessel pressure 


\section{Pipeline dewpoint at 4C seawater temperature}

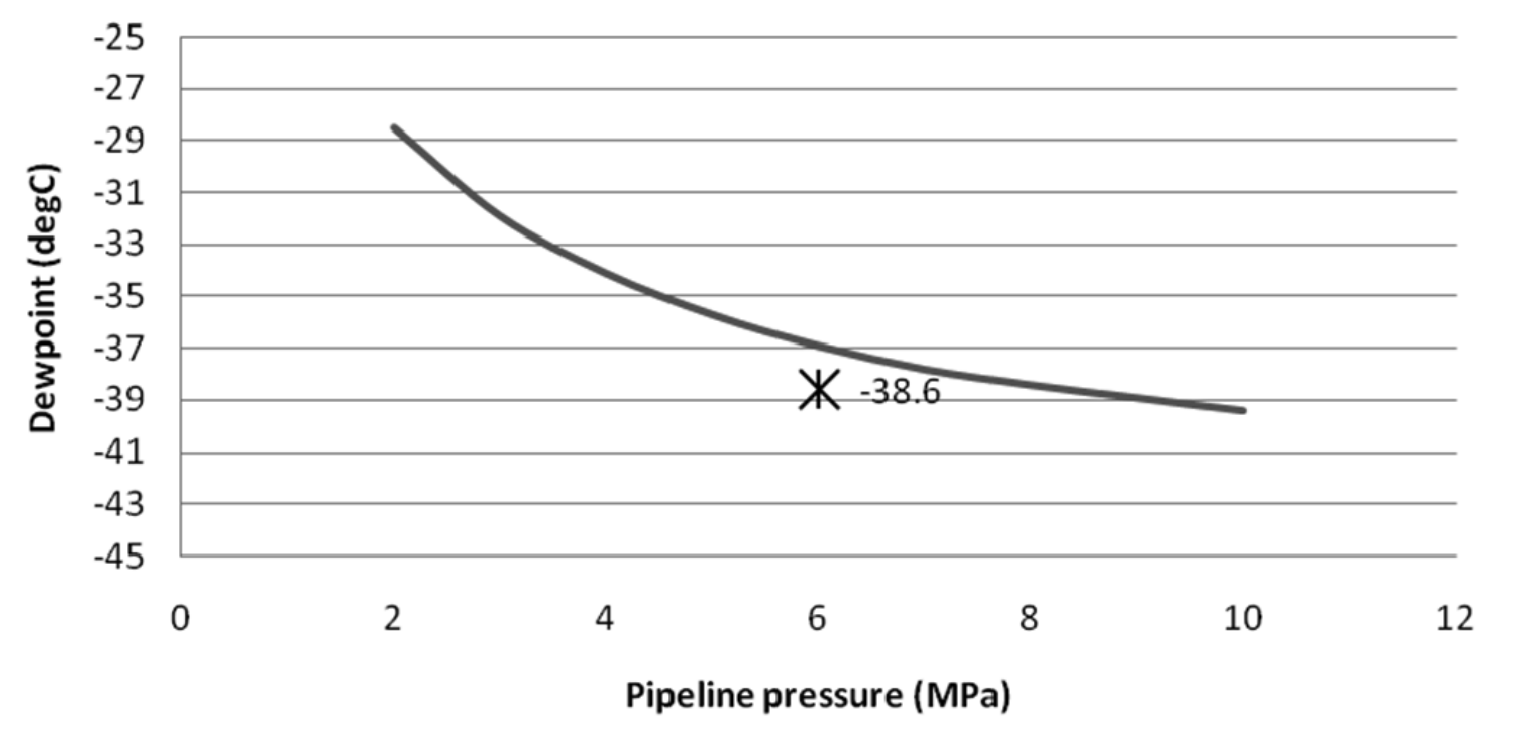

Figure 10: Predicted dewpoint versus dewpoint line for pipeline gas 


\begin{tabular}{|l|l|l|l|l|}
\hline Component & $\begin{array}{l}\text { Total mole } \\
\text { fraction }\end{array}$ & $\begin{array}{l}\text { Vapour } \\
\text { phase }\end{array}$ & $\begin{array}{l}\text { Liquid } \\
\text { phase }\end{array}$ & $\begin{array}{l}\text { Aqueous } \\
\text { phase }\end{array}$ \\
\hline Methane & $65.35 \%$ & $67.99 \%$ & $45.02 \%$ & $0.0007 \%$ \\
\hline Ethane & $13.86 \%$ & $13.92 \%$ & $14.07 \%$ & $0.00 \%$ \\
\hline Propane & $8.91 \%$ & $8.64 \%$ & $11.86 \%$ & $0.00 \%$ \\
\hline i-Butane & $0.95 \%$ & $0.89 \%$ & $1.52 \%$ & $0.00 \%$ \\
\hline n-Butane & $3.34 \%$ & $3.09 \%$ & $5.76 \%$ & $0.00 \%$ \\
\hline i-Pentane & $0.50 \%$ & $0.45 \%$ & $1.04 \%$ & $0.00 \%$ \\
\hline n-Pentane & $0.99 \%$ & $0.87 \%$ & $2.14 \%$ & $0.00 \%$ \\
\hline n-Hexane & $0.99 \%$ & $0.81 \%$ & $2.64 \%$ & $0.00 \%$ \\
\hline n-Heptane & $0.99 \%$ & $0.75 \%$ & $3.16 \%$ & $0.00 \%$ \\
\hline n-Octane & $0.99 \%$ & $0.69 \%$ & $3.73 \%$ & $0.00 \%$ \\
\hline n-Nonane & $0.99 \%$ & $0.63 \%$ & $4.31 \%$ & $0.00 \%$ \\
\hline n-Decane & $0.83 \%$ & $0.47 \%$ & $4.11 \%$ & $0.00 \%$ \\
\hline Carbon dioxide & $0.18 \%$ & $0.18 \%$ & $0.15 \%$ & $0.0033 \%$ \\
\hline Nitrogen & $0.13 \%$ & $0.14 \%$ & $0.07 \%$ & $0.0002 \%$ \\
\hline Water & $0.99 \%$ & $0.48 \%$ & $0.43 \%$ & $99.996 \%$ \\
\hline
\end{tabular}

Table 1: Wellhead stream composition 


\begin{tabular}{|l|l|}
\hline Property & Value \\
\hline Wellhead pressure & $15 \mathrm{MPa}$ \\
\hline Wellhead temperature & $80 \mathrm{C}$ \\
\hline Gas production rate & $105,000 \mathrm{sm}^{3} / \mathrm{hr}(89 \mathrm{MMSCFD})$ \\
\hline Condensate production rate & $55 \mathrm{~m}^{3} / \mathrm{hr}(8,300 \mathrm{bpd})$ \\
\hline $\begin{array}{l}\text { Wellhead gas stream water content } \\
\text { (vapour and liquid phase) }\end{array}$ & $1 \%$ \\
\hline Pipeline pressure & $6 \mathrm{MPa}$ \\
\hline Seawater temperature & $4 \mathrm{C}$ \\
\hline
\end{tabular}

Table 2: Assumed wellhead conditions 


\begin{tabular}{|l|l|}
\hline \multicolumn{2}{|l|}{ Tube-shell heat exchanger configuration } \\
\hline Number of shell passes/ shells in series & $2 / 2$ \\
\hline Tube passes per shell & 2 \\
\hline Baffle type & Single, $20 \%$ baffle cut \\
\hline Number of tubes per shell & $16,60 \mathrm{~mm}$ pitch, triangular layout \\
\hline Tube sizing & $\begin{array}{l}\text { Outside diameter: } 40 \mathrm{~mm} \\
\text { Wall thickness: } 2 \mathrm{~mm}\end{array}$ \\
\hline Thermal parameters & $\begin{array}{l}\text { Tube conductivity: } 43 \mathrm{~W} / \mathrm{m} . \mathrm{K} \\
\text { Counter flow (first pass) }\end{array}$ \\
\hline Operating assumptions & \multicolumn{2}{|l|}{} \\
\hline Tube section & $\begin{array}{l}\text { Inlet temperature: } 28 \mathrm{C} \\
\text { Outlet temperature: } 25 \mathrm{C}\end{array}$ \\
\hline Shell section & $\begin{array}{l}\text { Inlet temperature: } 2.6 \mathrm{C} \\
\text { Outlet temperature: } 14.0 \mathrm{C}\end{array}$ \\
\hline Split of cold gas passed to shell stage & $70 \%(2,127 \mathrm{Kgmol} / \mathrm{hr})$ \\
\hline No thermal losses to seawater, no tube fouling, vertical orientation \\
\hline Calculated heat exchanger sizing and performance \\
\hline Heat exchanger volumes per shell & $\begin{array}{l}\text { Tubes: } 0.16 \mathrm{~m}^{3} \\
\text { Shell: } 0.47 \mathrm{~m}^{3}\end{array}$ \\
\hline Heat exchanger dimensions & $\begin{array}{l}\text { Tube length: } 9.7 \mathrm{~m} \\
\text { Shell diameter: } 0.30 \mathrm{~m}\end{array}$ \\
\hline Overall UA & $\begin{array}{l}77.8 \mathrm{MJ} / \mathrm{h} . \mathrm{K}\left(\text { area } \mathrm{A}: 39 \mathrm{~m}^{2}\right) \\
\mathrm{U}=2.0 \mathrm{MJ} / \mathrm{h} . \mathrm{m}^{2} \mathrm{~K}\end{array}$ \\
\hline
\end{tabular}

Table 3: Design parameters for tube-shell heat exchanger 


\begin{tabular}{|l|l|l|l|l|}
\hline & Total & Vapour Phase & Liquid Phase & $\begin{array}{l}\text { Aqueous } \\
\text { Phase }\end{array}$ \\
\hline Fraction & $100 \%$ & $83.3 \%$ & $16.3 \%$ & $0.4 \%$ \\
\hline Temperature $(\mathrm{C})$ & 25 & 25 & 25 & 25 \\
\hline Pressure $(\mathrm{MPa})$ & 14.9 & 14.9 & 14.9 & 14.9 \\
\hline Mass flow $(\mathrm{Kg} / \mathrm{hr})$ & 122,787 & 99,698 & 22,717 & 372 \\
\hline Molecular weight & 26.1 & 25.4 & 29.7 & 18.0 \\
\hline Mass density $\left(\mathrm{Kg} / \mathrm{m}^{3}\right)$ & 296 & 284 & 360 & 1,012 \\
\hline
\end{tabular}

Table 4: Properties of stream leaving heat exchanger 


\begin{tabular}{|l|l|}
\hline \multicolumn{2}{|l|}{ Inlet conditions and operating parameters } \\
\hline Inlet temperature & $25 \mathrm{C}(77 \mathrm{~F})$ \\
\hline Inlet pressure & $14.9 \mathrm{MPa}(2188 \mathrm{psia})$ \\
\hline Nozzle pressure drop & $8.9 \mathrm{MPa}(1307 \mathrm{psia})$ \\
\hline Flow rate & $105,000 \mathrm{sm}^{3} / \mathrm{hr}(89 \mathrm{MMSCFD})$ \\
\hline Calculated conditions & \\
\hline Outlet pressure & $6 \mathrm{MPa}(881 \mathrm{psia})$ \\
\hline Outlet temperature & $2.6 \mathrm{C}(36.7 \mathrm{~F})$ \\
\hline Outlet water content & $113 \mathrm{mg} / \mathrm{m}^{3}(7 \mathrm{lb} / \mathrm{MMSCF})$ \\
\hline
\end{tabular}

Table 5: Predicted dehydration performance of defined scenario 


\begin{tabular}{|l|l|l|l|}
\hline Property & Condensate & Dry Gas & Water \\
\hline Temperature $(\mathrm{C})$ & 2.6 & 2.6 & 2.6 \\
\hline Pressure $(\mathrm{MPa})$ & 6.0 & 6.0 & 6.0 \\
\hline $\begin{array}{l}\text { Molar flow } \\
\text { (kgmol/hr) }\end{array}$ & 880 & 3,039 & 1.07 \\
\hline Mass flow $(\mathrm{kg} / \mathrm{hr})$ & 39,066 & 60,613 & 19.2 \\
\hline Molecular weight & 44.4 & 19.9 & 18.0 \\
\hline Mass density $\left(\mathrm{kg} / \mathrm{m}^{3}\right)$ & 516 & 70.6 & 1,026 \\
\hline
\end{tabular}

Table 6: Properties of streams leaving the dehydration vessel 


\begin{tabular}{|l|l|l|l|}
\hline Composition & Condensate & Dry Gas & Water \\
\hline Methane & $30.7 \%$ & $80.7 \%$ & $46 \mathrm{ppb}$ \\
\hline Ethane & $18.7 \%$ & $12.4 \%$ & 0 \\
\hline Propane & $20.3 \%$ & $5.0 \%$ & 0 \\
\hline i-Butane & $2.7 \%$ & $0.33 \%$ & 0 \\
\hline n-Butane & $10.0 \%$ & $0.91 \%$ & 0 \\
\hline i-Pentane & $1.6 \%$ & $0.07 \%$ & 0 \\
\hline n-Pentane & $3.2 \%$ & $0.12 \%$ & 0 \\
\hline n-Hexane & $3.1 \%$ & $0.05 \%$ & 0 \\
\hline n-Heptane & $2.9 \%$ & $0.02 \%$ & 0 \\
\hline n-Octane & $2.6 \%$ & $0.01 \%$ & 0 \\
\hline n-Nonane & $2.3 \%$ & $0.00 \%$ & 0 \\
\hline n-Decane & $1.7 \%$ & $0.00 \%$ & 0 \\
\hline Carbon dioxide & $0.2 \%$ & $0.19 \%$ & $67 \mathrm{ppm}$ \\
\hline Nitrogen & $0.0 \%$ & $0.17 \%$ & $2.1 \mathrm{ppm}$ \\
\hline Water & $141 \mathrm{ppm}$ & $149 \mathrm{ppm}$ & $99.99 \%$ \\
\hline
\end{tabular}

Table 7: Compositions of streams leaving the dehydration vessel 